\title{
Arte en la necrópolis PREHISpánica
}

\section{de Tierradentro}

\author{
Elías Sevilla Casas \\ Doctor en Antropología, Northwestern University. InVESTigador grupo \\ Arqueodiversidad, Facultad de Artes Integradas, Universidad del Valle, Cali \\ eliasevilla@gmail.com
}

\begin{abstract}
Resumen
PARTIR DE UNA BREVE DESCRIPCIÓN DE LA OBRA ARQUITECTÓNICA, ESCULTÓRICA Y PICTÓRICA DE LAS

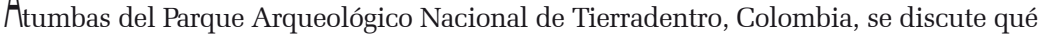
significa "necrópolis", “arte” y "prehispánico"; basado en literatura reciente sobre antropología del arte y arte prehispánico, desde una lectura que se aparta de categorías, conceptos y términos anglo y eurocentrados. Se presta atención al "tejido pétreo" y "la petridad abstracta" característicos del arte prehispánico de la necrópolis, para entender su funcionalidad reduplicativamente simbólica, es decir, como una elaboración en el campo simbólico general en que se mueven los seres humanos, porque apela a la capacidad de significación que ciertos artefactos tienen para los productores-receptores. Se habla desde la arqueología, sin especulaciones mitopoéticas, sobre las poblaciones prehispánicas que crearon y usaron la necrópolis. Luego se reflexiona sobre la experiencia estética que se puede generar en los visitantes que se mueven en el campo "arte y cultura".

Palabras Clave: Tierradentro, arte prehispánico, necrópolis, antropología del arte, arqueología, patrimonio cultural de la humanidad, experiencia estética
\end{abstract}

\section{Art in the pre-Hispanic necropolis of Tierradentro}

\begin{abstract}
BRIEF DESCRIPTION IS MADE OF THE ARCHITECTURAL, SCULPTURAL AND PICTORIAL WORK FOUND IN THE Atombs of the National Park of Tierradentro, Colombia, in order to discuss what "necropolis", "art" and "pre-Hispanic" mean. The study takes into account recent literature on anthropology of art and pre-Hispanic art, a following an emerging tendency that departs from the exclusive Euro and Anglo centered categories, concepts and terms. The idea is to mind the "stone thread" and the "abstract stoniness" that characterize the pre-Hispanic Andean art found in the necropolis in order to understand its reduplicative symbolic functionality. This is an elaboration within the general symbolic realm of human activity stemming from the emphasis on the special ability for signification that some human made things for the producers-receivers. We deal with what archaeology allows saying, without mythical-poetic speculations, on the pre-Hispanic populations who created and used the necropolis; and, on the aesthetic experience that the necropolis, as it is today, can generate in the visitors that move within the realm of "art and culture".

KEY WORDS: Tierradentro, pre-Hispanic art, necropolis, anthropology of art, archaeology, world heritage, aesthetic experience
\end{abstract}

Revista Colombiana de Antropología

Volumen 45 (2), julio-diciembre 2009, pp. 369-397 


\section{INTRODUCCIÓN}

NA LECTURA DESDOBLADA DEL TíTULO DEL PRESENTE ARTíCULO COMPRUEBA
que nos encontramos atrapados de forma ineluctable, y tal vez
inevitable, en redes categoriales, conceptuales y lingüísticas. Ellas hacen que lo dicho se enuncie siempre desde una posición que no es del todo absoluta y que obliga a mirar y describir el mundo desde determinada perspectiva (Nehamas, A., I985, pp. 42-73). Esto es lo que sucede en el presente caso de la necrópolis de Tierradentro, Cauca. "Arte" es una construcción relativa al mundo euro y anglocentrado, que algunos han llamado Occidente. "Prehispánico" tiene un sentido etimológico con relación a hispánico, como lo sería el término alterno "precolombino" con relación a Colón, e inclusive "prehistórico" que supone, para muchos, que lo "pre-" está fuera de la historia (la construida según los cánones occidentales). "La tierra adentro" fue el nombre otorgado por los conquistadores españoles a un gran conjunto de abruptas montañas habitadas por indios muy aguerridos que se interponían en el camino que, en lo que hoy llamamos Colombia, iba de Santafé a Popayán y pasaba por Neiva. Hoy, Tierradentro corresponde al área de dos municipios caucanos, Inzá y Páez, que albergan a una población de 60 mil personas distribuidas en un $43 \%$ de mestizos y afrodescendientes y $57 \%$ que se declaran indígenas de mayoría nasa, quienes llaman nasakiwe a esas tierraterritorio. "Necrópolis" es una palabra de origen griego que quiere decir "ciudad de los muertos". Los dirigentes y líderes nasa de la zona comienzan a hablar, con respecto a la necrópolis que nos ocupa, de ju'gtewe'sx çxab, "la ciudad de nuestros mayores antepasados". Es un intento por aproximarse, con propósitos pragmático-políticos, reforzados por elaboraciones cosmológicas recientes, a un elemento de su territorio que hasta ahora les había suscitado desdén y temor sacro (Sevilla, E. y Piñacué, J. C., 2008). En el mundo de la arqueología y del turismo, Tierradentro es el Parque Arqueológico, situado en el corregimiento de San Andrés de Pisimbalá, municipio de Inzá, Resguardo de San Andrés. En I995 fue incluido por la Organización de las Naciones Unidas para la Educación, la Ciencia y la Cultura, UNESCO, en la honrosa lista de Sitios de Patrimonio Cultural de la Humanidad, al lado de Cartagena, Mompox y San Agustín. Estos cuatro lugares son los únicos que Colombia ha logrado que sean aceptados en la Lista del Patrimonio Cultural Mundial. El parque de los Katíos y 
la isla de Malpelo igualmente fueron aceptados en la mencionada lista del Patrimonio Natural Mundial.

El presente estudio intenta hacer una descripción y análisis de la cuestión qué significa hablar de "arte", de "necrópolis" y de "prehispánico" teniendo como referente empírico la necrópolis de Tierradentro. El ejercicio se hará por medio de la consulta de la más reciente literatura mundial sobre "antropología del arte" y "arte prehispánico", dentro de una naciente tendencia que prefiere hablar de un "sistema singular de metáforas" que, en el caso andino prehispánico, busca realizar interpretaciones en sus propios términos sobre el "tejido en piedra" y la "petridad abstracta" que son característicos de esta tradición "artística" (Paternosto, C., 1986). Trataremos de precisar, hasta donde la arqueología lo permita, qué pudo significar esta combinación de arquitectura, escultura y pintura para los productores-receptores originarios y qué puede representar para nosotros cuando hoy visitamos la necrópolis. Para este propósito trabajamos una propuesta conceptual que elabora el concepto de funcionalidad reduplicativamente simbólica que la necrópolis parece haber tenido en el hondo pasado y la que tiene hoy para nosotros.

Como dice S. Vogel (2006, p., 217), al referirnos al "arte africano", somos nosotros los que debemos resolver el dilema de si lo prehispánico es arte o no, pues "es nuestro problema". Sobre la funcionalidad simbólica en el pasado prehispánico sólo podemos inferir con los arqueólogos, a partir de bases no muy elocuentes y sin acceso a ningún código de escritura, algunos elementos generales. Hay sugerencias en la literatura especializada centro-andina de que en esas sociedades la apreciación propiamente estética parece no haber sido predominante. ${ }^{1}$

I. La experiencia estética, dice S. Vogel (2006, p. 2I7) es universal, así algunas culturas no tengan conceptos o términos para ella, no la hagan explícita o no le den dominancia. E. Pasztory (I997) sugiere que la función estética de las cosas hechas (artefactos), que producen sentido particularmente por sus propiedades formales y de estilo, era implícita en América antigua, con excepción tal vez, del caso de los maya en el período clásico quienes fueron más explícitos. Es importante recordar que el clásico de la antropología del arte, Primitive Art de F. Boas (I928), ya insistía en estas propiedades formales y de estilo, lo mismo que en el virtuosismo para producirlas. Décadas más tarde A. Gell (I992) hablará de "la tecnología del encantamiento y el encantamiento de la tecnología". El artista abstracto C. Paternosto (I986, p. 6) especialista en arte inca, cita a G. Kubler para concluir que "en el contexto de la América precolombina la experiencia estética pura era desconocida". 


\section{LA NECRÓPOLIS}

$\left[\begin{array}{l}\mathrm{S} \\ \mathrm{n}\end{array}\right.$ STE TÉRMINO HA SIDO POCO APLICADO EN LA LITERATURA ANTROPOLÓGICA Y arqueológica con respecto a los conjuntos de tumbas subterrá- neas, talladas en roca blanda de origen volcánico (tobas andesíticas), que constituyen el motivo principal por el que el Parque Arqueológico de Tierradentro es reconocido. Los términos usuales han sido los de tumbas e hipogeos y algunos más especializados en el medio arqueológico son los de tumbas de pozo y cámara o tumbas de tiro y cámara. Hasta ahora, la mirada se ha centrado en determinadas tumbas singulares y, por los restauradores, en determinados aspectos de las mismas. El conjunto de las cuatro concentraciones de tumbas en los altos de Segovia, El Duende, San Andrés y el Aguacate, que enmarcan el vallecito de la quebrada de San Andrés, ha recibido poca atención, excepto en los planes turísticos (cuya literatura a veces sí habla de necrópolis). De igual forma, los expertos de la Lista de Patrimonio Mundial también hablan de necrópolis. Obviamente, la palabra implica conjunto, sea de las tumbas de cada alto, sea — como aquí se prefiere- de los cuatro altos como un todo. En su tesis de maestría para la Universidad Nacional Autónoma de México, UNAM, la arquitecta G. Preciado (I996) argumenta a favor del uso de este término y relaciona la necrópolis de Tierradentro con los modos prehispánicos de enterramiento secundario mesoamericano, de los que hace un recuento comparativo. Conviene repetir que los dirigentes indígenas nasa en su movilización de reivindicación étnica y organización político económica miran también el conjunto y le aplican de manera muy consciente el ya mencionado término de ju'gtewe'sx çxab, "la ciudad de nuestros mayores antepasados". El turismo asociado a la necrópolis es para estos jóvenes nasa uno de los principales atractivos de la reivindicación.

El Comité Consultivo de la UNESCO acogió en I995 la propuesta del Estado colombiano de incluir a Tierradentro en la Lista de Sitios de Patrimonio Cultural de la Humanidad y caracterizó la necrópolis de los cuatro altos bajo los siguientes criterios (UNESCO/WH, Advisory Body Evaluation, I995, p. I):

(iii): Tumbas subterráneas con cámara lateral se han encontrado en el conjunto de la América nuclear, desde México hasta el noroeste de Argentina, pero la más grande concentración está en Colombia (seguida por Ecuador). Sin embargo, no es sólo el número y la con- 
Volumen 45 (2), julio-diciembre 2009

centración de estas tumbas en Tierradentro lo que es único. Estos hipogeos consistentes en un pozo vertical, escaleras helicoidales, vestíbulo y cámara lateral con columnas y pilastras alrededor de una gran planta oval, y, en particular, representaciones antropomórficas esculpidas y pinturas policromas son únicos en América. Estas estructuras funerarias de gran complejidad arquitectónica son testimonio excepcional de una sociedad que ha desaparecido.

Los seis criterios bajo los que un determinado sitio en el mundo puede ser reconocido como de "sobresaliente valor universal" han tenido una larga historia de formulación y depuración consensuada (ICOMOS, 2008). El criterio (iii) en I994, cuando se aplicó a Tierradentro, estaba formulado así: la propiedad en cuestión debía "procurar un único o por lo menos excepcional testimonio de una tradición cultural o de una civilización que ha desaparecido". Como se ve en la cita, la necrópolis de Tierradentro fue considerada un testimonio único en América. Entre los sitios más parecidos a Tierradentro que, sin ser necesariamente necrópolis, recibieron la misma clasificación bajo el criterio iii están el Valle de M'Zab en Argelia (ref. 188)², el pueblo de Itchan Kala en Uzbequistán (ref. 543), el Valle Bajo de Awash en Etiopía (ref. Io), las ruinas arqueológicas de Moenjodaro en Pakistán (ref.I38), la Acrópolis de Atenas en Grecia (ref. 404) y el complejo neolítico de Stonehenge-Avebury

2. La referencia es al número de serie de los Sitios de la Lista del Patrimonio Mundial de la UNESCO, que permite entrar a la descripción oficial de cada uno. Pueden visitarse en http:// whc.unesco.org/en/list. en Inglaterra (ref. 373).

El otro criterio que se aplicó a Tierradentro fue el (i) que, para la fecha de 1994 rezaba de la siguiente manera: El sitio "representa un único logro artístico, una obra maestra del genio creativo humano". En I996 el texto se cambió para decir: "Representa una obra maestra del genio creativo humano". La justificación para incluir a Tierradentro bajo este criterio se desglosó así:

(i): La simetría simbólica lograda entre las casas de los vivos afuera y los hipogeos para los muertos, mediante un número limitado pero elegante de elementos no sólo transmite una agradable sensación estética sino que también evoca una imagen poderosa de la importancia del nuevo estado en que el difunto ha entrado y la continuidad entre la vida y la muerte, entre los vivos y los ancestros. Los que entran a los hipogeos entran al suelo primordial y son sensibilizados frente a los códigos y valores de los constructores, a lo largo del tiempo, por la dignidad lograda en las cámaras. 
Entre los sitios, análogos a Tierradentro, que fueron acogidos bajo este criterio (i) de "obra maestra del genio creativo humano" figuran el Parque Nacional Rapa Nui en Chile (ref.7I5); los círculos megalíticos de Senegambia (ref. I226); y, de nuevo, el complejo Stonehenge-Avebury.

Entre las tumbas de entierro secundario de pozo y cámara que constituyen la necrópolis de los cuatro altos demarcados en Tierradentro como Parque Arqueológico, hay que distinguir, en primer lugar, las que han sido abiertas y luego tapadas, sea por guaqueros (las más) sea por arqueólogos o personas autorizadas por el Instituto Colombiano de Antropología e Historia, ICANH, que es el organismo a cargo de estos bienes arqueológicos. Hay algunas cuyo estado visible indica que han colapsado sin saber si fueron abiertas antes o no. Con pocas excepciones, las tumbas tapadas o colapsadas no cuentan con información sobre la estructura y contenido. Los planos disponibles (confirmados para el caso de Segovia por la inspección ocular de una persona experimentada en las artes de la guaquería, enero de 2009), permiten hablar tentativamente de la siguiente distribución en los tres altos que han recibido la mayor atención del ICANH:

- Segovia: 25 abiertas, 39 tapadas, o colapsadas.

- El Duende: 5 abiertas, 8 tapadas, o colapsadas.

- San Andrés: 6 abiertas, i6 tapadas y I colapsada.

El cuarto alto, El Aguacate, es un caso especial. Por su difícil acceso topográfico y, tal vez, por estar fuera de los terrenos escriturados del Parque —es decir, por estar directamente en terrenos del resguardo de San Andrés- las tumbas han recibido un tratamiento menos diligente que el de los otros altos, incluida la identificación. El trabajo de campo permitió establecer, o confirmar, varios puntos importantes:

I. En los alrededores del área demarcada como "de los hipogeos" hay abundantes tumbas, posiblemente de fosa simple similar a la de entierros primarios hallados por A. Chaves y M. Puerta (I980) en San Francisco y Santa Rosa, fuera del área de El Parque. Aquí no se tienen en cuenta.

2. En la zona demarcada hay 20 tumbas tapadas, algunas de las cuales parecen colapsadas y 4I tumbas abiertas; de estas I6 son de estructura sencilla (pozo con escalas y cámara oval, sin pilastras, columnas, nichos, bajo/alto relieves, ni pintura) y 25 
tienen características especiales por su estructura arquitectónica o sus elementos complementarios en relieve o pintura.

3. De las 4I abiertas sólo dos tienen protección de la intemperie por estar bajo cobertizos de cinc; el resto, incluyendo las que tienen características especiales, están a la intemperie, semillenas de tierra húmeda rodada y maleza. A diferencia de los otros altos, El Aguacate recibe sólo una visita semanal de inspección por parte de los empleados-vigilantes de El Parque.

En resumen, por lo hasta ahora comprobado en terreno, los cuatro altos, en las áreas delimitadas como Parque, albergan 78 tumbas abiertas y un incierto número (alrededor de 94) entre tapadas y colapsadas. Sólo un trabajo cuidadoso que implique planos del subsuelo realizados con instrumentos de inducción electromagnética permitirá conocer la lista y la condición precisa de las tumbas no abiertas que hay en las zonas demarcadas como constitutivas de El Parque Arqueológico, es decir de la necrópolis de Tierradentro. Una descripción detallada de la situación de cada una de las tumbas en cuanto a su estado de conservación se encuentra en el reciente informe de E. Sevilla (2009).

Por sus características, que se bosquejarán enseguida, la necrópolis de Tierradentro es única en el mundo. Se cuenta entre el selecto número de construcciones funerarias arcaicas que la UNESCO incluyó en su Lista. En ella aparecen, como análogas en cuanto que son necrópolis, las Tumbas del Antiguo Reino de Koguryo (Corea; ref. I09I), Memphis, su Necrópolis y los Campos de Pirámides desde Giza a Dahshur (Egipto; ref. 86), el Pueblo Púnico y la Necrópolis de Kerkuane (Túnez; ref. 332bis), las Cuevas de Skocjan (Eslovenia, ref. 390), las Cuevas de Elephanta (India; ref. 244rev), los Sitios Arqueológicos de Micenas y Tiryns (Grecia; ref. 94I) y la Necrópolis Estrusca de Cerveteri y Tarquinia (Italia; ref. II58).

\section{Caracterización elemental}

DE LA ARQUITECTURA, ESCULTURA

Y PINTURA DE LAS TUMBAS

L PRESENTE ESTUDIO SUPONE FAMILIARIZACIÓN CON LA NECRÓPOLIS, Condición que no es válida para algunos lectores. Como el Lespacio disponible y el medio de publicación impiden hacer honor a la riqueza y variación de lo allí encontrado, es necesario 
3. La visita a este sitio web se considera complementaria a la lectura del presente texto y sería muy útil si se hace antes de continuar con la lectura. que quien no conoce Tierradentro en persona, o desea refrescar su conocimiento, visite un sitio vicario, cibernético, www.tierradentro. info $^{3}$, construido para permitir conocer detalles de la necrópolis, incluida una galería fotográfica que capta propiedades formales y de estilo, a más de datos sobre conservación, entre ellos el ya mencionado informe de E. Sevilla (2009). Se habla de caracterización elemental porque se atiende aquí sólo a unos pocos criterios relacionados con "el arte" y porque una bien sustentada y completa implica una ardua labor de arquitectura, escultura, pintura y otras disciplinas complementarias.

La totalidad de las 78 tumbas abiertas de la necrópolis pertenecen al tipo denominado de pozo (o tiro) y cámara (TPC, en adelante) en la literatura (shaft tombs, en inglés). El pozo vertical tiene entrada a una cámara lateral que se ha labrado en el subsuelo. Por necesidades estructurales las TPC no ocurren en cualquier parte pues necesitan un subsuelo que sea resistente pero no tanto que impida trabajarlo con instrumentos que no siempre fueron metálicos (en Tierradentro con seguridad fueron líticos). Las rocas blandas como la caliza o la toba volcánica (cenizas compactadas) son perfectas para este propósito y las de San Andrés fueron utilizadas por lo mismo. Al parecer la construcción de TPC en roca viva se hizo para enterramientos secundarios colectivos destinados a ser visitados después. Otros fuera de la zona, en cambio, se cerraron de forma definitiva una vez se depositaron allí los cuerpos de los muertos. J. A. Ford (1944, fig. 2, p. I8) en su estudio de las tumbas del Valle del Cauca y Cauca muestra que ciertos pozos de TPC fueron rellenados con grandes piedras para impedir el acceso, una vez realizado el entierro. Algunos de los hipogeos en el mundo son famosos por la riqueza del ajuar funerario allí encontrado, lo que ha atraído a los saqueadores desde hace miles de años. Las pesadas losas o las puertas falsas (que ocurren en particular en Egipto) han sido respuesta, también milenaria, de los constructores a esta amenaza. La arqueología y la protección del patrimonio han sido las más perjudicadas con la intervención destructiva de los saqueadores o guaqueros (como se les llama en Colombia).

La distribución de TPC en el Nuevo Mundo está concentrada en el oeste de México y al norte de Suramérica (Ecuador y Colombia), aunque también hay algunas dispersas en el resto del 
continente (Long, S., 1967). En Colombia hay una amplia gama de tipos de tumbas prehispánicas primarias y secundarias, entre las cuales las TPC son algo escasas. Se las ha encontrado fuera de Tierradentro (Gutiérrez S. de, y García L. de, (s. f.); Ford J. A., (1944); Long, S., 1967) pero por la concentración y complejidad arquitectónica y pictórica que presenta esta necrópolis es en efecto un sitio único en el mundo.

La literatura arqueológica sobre las TPC se centra en el caso del oeste mexicano y habla, al respecto, de una "tradición de tumbas de tiro y cámara”. Estas publicaciones focalizadas tienen pocas referencias, no sólo sobre Suramérica sino sobre otros casos del resto del mundo. Esta "tradición" ha enfocado más su atención en los bienes funerarios allí encontrados (grave goods), en particular por los saqueadores, que en la organización espacial, los contextos, y los componentes de la obra arquitectónica (ver artículos y referencias en Fowler, W. R., Beeckman, C. S. y Pickering, R. B. (2006); Taylor, R. E., I970). Tierradentro, a pesar de la abundancia de TPC, de su amplia gama en la tipología arquitectónica y de pintura y escultura, no se menciona en estas referencias. Quizás una de las causas del olvido sea porque los bienes funerarios encontrados en las excavaciones profesionales han sido escasos y "pobres" (poco oro y elementos preciosos, cerámica funeraria) y porque de lo hallado por los guaqueros se sabe muy poco.

Aparte del tiro o pozo con escaleras, que es común a todas sus tumbas, Tierradentro muestra una amplia gama de variaciones estructurales que se puede apreciar con los diagramas de corte y planta elaborado por los investigadores (Ayala, L., 1986; Chaves, A. y Puerta, M., I986; Preciado, G., 2006) y que se presentan en el sitio de internet mencionado. Esta tipología de tumbas va desde las simples, que tienen una puerta que comunica directamente la escalera recta lineal con la cámara, hasta las más complejas que tienen escaleras muy elaboradas, un bien definido vestíbulo y las cámaras. Estas varían desde las muy sencillas, con planta oval y techo abovedado, plano o inclinado y dimensiones pequeñas (unos 2.50 metros en el eje más largo de la planta) o mediana (cuatro metros de eje) hasta las muy grandes (8.8 metros de eje) y complejas. La profundidad varía entre 2.0 y 5.9 metros; las de El Aguacate se caracterizan por ser poco profundas y en general pequeñas o medianas y sencillas en la estructura. La complejidad 
de la cámara se manifiesta, por una parte, por la presencia de pilastras, nichos y columnas; por otra, en el techo que a veces adquiere una forma que replica, en sentir de muchos, la estructura de la cubierta en las casas de los vivos. La combinación de estos elementos en la necrópolis genera una gran variedad estructural que en muy pocos casos sacrifica la simetría del óvalo en la planta. En las menos complejas, las pilastras adheridas a la pared forman nichos u hornacinas, algunos de los cuales son profundos, como cámaras laterales. Es interesante observar que algunas escaleras en su parte final y vestíbulo son amplias, como para albergar varias personas a la vez. En las más complejas, las pilastras separadas de la pared de fondo han pasado al centro y forman masivas columnas. Las de mayor complejidad estructural llegan a tener tres columnas, seis pilastras y siete nichos.

Ciertas tumbas complementan la obra arquitectónica con la escultura (alto o bajo relieve) y la pintura. Los relieves son o bien boceles horizontales a media altura o nervios que remedan el caballete, las vigas, pares y tirantes del techo en las viviendas de los vivos tal como han sido reconstruidas por los arqueólogos (Chaves, A. y Puerta, M., 1988). Otras tienen estos boceles o nervios sólo en pintura. Son muy llamativos los relieves de figuras humanas estilizadas geométricamente que representan rostros (mascarones) o, incluso, el cuerpo completo con las extremidades recogidas. Las pictografías son de dos clases: geométricas abstractas las más, y naturalistas en casos excepcionales (estas sólo en El Aguacate). Juegan de manera variada con rombos, triángulos y líneas pintadas en rojo y negro sobre fondo blanco, buscando llenar todo el espacio, en una clara manifestación del horror vacui, esa obsesión de ciertas tradiciones artísticas por no dejar espacio vacío en las supeficies trabajadas.

En El Aguacate la pintura tiene más variedad de combinaciones geométricas que en los otros tres altos puesto que mezcla líneas, rectángulos con juegos de puntos y franjas de diversa forma. En algunas de sus tumbas aparecen dibujos naturalistas que no acusan el horror vacui porque están distribuidos puntualmente en la amplia bóveda, por lo demás, vacía de pictografías. Estas figuras han sido interpretadas como "lunas", "soles", "ciempiés" y "salamandras". En general, los "soles" tienen el núcleo en bajorelieve. También hay figuras que parecen tener rasgos antropomorfos o zoomorfos; el deterioro en que se encuentran impide precisarlas bien. En dos de las tumbas la bóveda aparece partida 
en franjas trilineales horizontales, que dividen la pared-bóveda en dos partes, que han sido interpretadas como separación entre "el cielo" (con "lunas") y "la tierra” (con "salamandras"). Otra característica de El Aguacate es la presencia del amarillo ocre (casi crema), que no se observa en las otras lomas. La sobriedad casi minimalista de algunas de las tumbas en este alto y su marcado naturalismo pueden ser indicios de una micro tradición diferente en el conjunto de la necrópolis del valle de San Andrés.

\section{Arte EN LA NECRÓPOLIS PREHISPÁNICA}

$\uparrow$ ne

IERRADENTRO APARECE EN LA LITERATURA ARQUEOLÓGICA COMO PERTEneciente al gran complejo denominado Alto Magdalena, que incluye las zonas de San Agustín-Isnos y el Valle del Río La Plata. R. Drennan (2008) y (2000) da una visión panorámica y resumida de esta literatura. C. H. Langebaek (I998), C. H. Langebaek, A. Dever y J. Blick (200I) y C. H. Langebaek y A. Dever (2009, en este mismo número) tienen información reciente que nos exime de extendernos aquí. En resumen, lo hallado hasta ahora apunta a que en el Valle de San Andrés y cuencas vecinas de los ríos Ullucos y río Negro aparecen asentamientos dispersos y de baja densidad, con uso de suelos para agricultura, desde hace unos 3000 AP. Hacia el 2400 AP, al final del llamado Período Temprano I, hay un ligero crecimiento de ocupación en San Andrés y algo en la cuenca del río Negro, aunque se mantiene el patrón disperso que persiste durante el Temprano 2. Entre 2IOO y I9O0 AP, Temprano 3, aparecen los primeros signos de concentración y formación de aldeas en el llano de Segovia. Este patrón se mantiene durante el largo período Medio hasta el 700 AP cuando se inicia el Tardío. La cuenca de la quebrada San Andrés y las de los ríos Ullucos y río Negro aparecen también ocupadas y más densas. La tendencia sigue, no con el mismo impulso, durante el Tardío que, según los datos de cerámica, se extiende hasta el 350 AP e implica como ocupadas las partes medias-altas de los ríos Ullucos y río Negro. Es de advertir que hacia el 500 AP llegaron los españoles a la zona (en el I537 DC) y que encontraron a los páez, hoy autodenominados nasa, como los habitantes de Tierradentro. Sus asentamientos se han caracterizado, desde tiempos de la Conquista hasta bien avanzado el siglo XX, por ser sistemáticamente dispersos. Los 
correspondientes mapas, en versión detallada, pueden verse en el sitio de internet mencionado.

Los datos arqueológicos apuntan, por tanto, a que los constructores y usuarios originales de la necrópolis fue gente que vivía en asentamientos nucleados y que eran horticultores. La investigación realizada en el Valle de La Plata (Quattrin, D. W., 200I), para esa misma época y en condiciones ecológicas similares, indica que producían maíz, fríjol, calabaza, ají, yuca y batata, complementados con diferentes productos silvestres, entre ellos las moras. En el período de más alta concentración, en el Medio, las aldeas en la cuenca

4. Es interesante anotar que según cálculos recientes de la Corporación Regional del Cauca (CRC, 2002) en todo el conjunto del Resguardo de San Andrés, con diez veredas y un radio geográfico comparable, no hay más de 550 hogares incluyendo los mestizos (lo que daría una población total inferior a 3 mil). Este dato confirma lo ya inferido por C. H. Langebaek y asociados (2009, en este mismo número) sobre el volumen demográfico en el período Moderno que sería inferior al calculado para el período Tardío en que al parecer se construyó la necrópolis. de San Andrés pudieron tener hasta 5 mil personas para zonas de radio entre Io y $15 \mathrm{~km}$, si se atiende a lo hallado en la cuenca de La Plata. ${ }^{4}$ Los investigadores coinciden en que la organización sociopolítica de estos poblados pudo implicar la existencia de elites cuya preeminencia no fue el resultado de control de buenas tierras u otros recursos económicos sino que tenía bases más de orden simbólico o ideológico. R. Drennan (2008, p. 388) sugiere que las tumbas pudieron servir "para entierros secundarios de considerable número de individuos en un patrón funerario que no enfatizaba la diferenciación jerárquica o mucha individuación mediante ofrendas, posicionamiento u otros rasgos". Sin embargo, en las tumbas hay diferencias en la complejidad y elaboración escultórica o pictórica, que no necesariamente tienen que estar relacionados con la evolución en el tiempo sino con posibles diferencias sociales de carácter sincrónico cuyas bases y forma aún no están bien determinadas por la arqueología.

\section{ARTE EN LA NECRÓPOLIS PREHISPÁNICA}

CE RECONOCIÓ AL INICIO QUE “ARTE” ES UNA CONSTRUCCIÓN EURO Y ANGLOcentrada. Es un vocablo incómodo, si se quiere obsoleto, pero inescapable, mientras no haya uno mejor, como herramienta de discurso analítico y crítico para quienes hoy analizamos el asunto. No hay un término-concepto alterno que cubra el dominio 
que, desde la sociología, H. Becker (I982) denominó Art Worlds y P. Bourdieu (1992) champ de l'art. E. Pasztory (2005, p. I3) sostiene que "el concepto de 'arte' estorba más que ayuda en nuestro análisis del mundo de las cosas" prehispánicas puesto que "los conceptos místicos de arte están asociados con el declinar de las cosas como medios comunicativos y son en sí mismos signos de pérdida y nostalgia”. Sin embargo, la autora no sólo ha escrito libros y artículos sobre Prehispanic Art, Aztec Art, Masterpieces of pre-Columbian Art, sino que el libro en que aparecen la citas traídas tiene como subtítulo Toward a New Vision of Art (subrayados del autor).

El Diccionario de la Real Academia Española, DRAE, nos dice que arte deriva del latín ars, que corresponde al griego techné hoy presente en tecnología. En consecuencia, la primera acepción de la voz ars es: "Virtud, disposición y habilidad para hacer algo". A este sentido alude R. Williams (I976, p. 40-43) cuando traza el inicio de la trayectoria del concepto en el mundo anglosajón. La evolución del significado asociado al término llevó a que artista, agente, se contraponga hoy no sólo a científico y tecnólogo sino a artesano y a operario. En el siglo XIX se consolidó el énfasis esteticista en el arte iniciado siglos antes. Terminó confinándole el sentido a la experiencia estética, entendida como fruición de lo bello. Este valor esteticista fue desvirtuado desde dentro del Art World eurocentrado, con la aparición del dadaísmo a inicios del siglo XX, con el desplante de M. Duchamp en 1917 y con las muchas variaciones que de este han ocurrido desde entonces. Por ello A. Danto (1994), al referirse a la consolidación del "pluralismo objetivo" de la producción artística posterior a los años 6o, habla del "arte después del arte", sin deshacerse de la incómoda palabra.

Tal vez el núcleo de sentido que persiste hoy detrás del término arte, ya advertido por R. Williams (I976, p. 4I), es el de la asociación con creación e imaginación. Es posible que estemos de retorno al sentido original de ars-techné con la precisión introducida, desde la antropología del arte por A. Gell (I992) quien habla de una conjunción (por alianza generadora de sentido entre el productor y la comunidad receptora) de una tecnología del encantamiento y un encantamiento de la tecnología.

En este orden de ideas, encantamiento corresponde a otra noción antropológica que es clave y es elaborada por P. Bourdieu 
(I984), la de magia propuesta por M. Mauss (I950, p. 134) cuando escribe que es:

\begin{abstract}
El arte de la producción pura, ex nihilo. Hace con las palabras y los gestos aquello que las técnicas hacen con el trabajo [...] evita el esfuerzo porque ha logrado reemplazar la realidad por las imágenes. Hace nada, o casi nada, pero hace creer todo, tanto más fácilmente cuanto pone al servicio de la imaginación individual las fuerzas y las ideas colectivas.
\end{abstract}

Como se sugirió en E. Sevilla (2007a, p. 68): "Esta magia en Mauss, se reduce, en fin de cuentas, a un poderoso efecto de creencia o, dicho a la inversa, de suspensión de la descreencia. Es una labor de taumaturgia". La expresión "suspensión de la descreencia" (suspension of disbelief) procede de T. Coleridge (1951, p. 254) en su interpretación del efecto del arte poético de W. Wordsworth. Implica pasar un umbral que deja atrás la preocupación profana, hecha de descreencia de todo, para sumirse en

5. En E. Sevilla (20076, p. 255) se hace una elaboración más detallada de este ingreso al mundo reduplicativamente simbólico del que la epifanía poética es una instancia preclara. una creencia (religiosa, estética, poética, erótica, etcétera). J. Joyce aplicó a este estado la expresión “epifanía” porque entonces se ve el mundo a otra luz. ${ }^{5}$

El efecto de creencia implicado en el arte prehispánico de Tierradentro tiene dos grandes sujetos colectivos de cuyos puntos de mira nos valdremos: los productores-receptores originales y los que después entran a esas cámaras no con el ánimo de saquear entierros sino de tener epifanías. Nosotros, los visitantes del siglo XX y XXI pertenecemos a la segunda categoría. Esas obras materiales como cosas, objetos o artefactos, están allí, porque se han recuperado o conservado, mal que bien. El sentido de ellas es relativo a los sujetos que, al creer en ellos, les dan un valor condicionado directamente por su cultura y contexto social. Esta valoración puede ser caracterizada hoy, para los fenómenos contemporáneos que vivimos, con los ya clásicos términos de valor de uso, valor de cambio, valor de signo y valor reduplicativamente simbólico. Un mismo objeto o proceso material puede ser valorado de manera distinta por sujetos diferentes e incluso por uno mismo, individual o colectivo, en diversos tiempos. Más aún, es decisivo entender que la estimación de estas materialidades por lo usual es compleja y dinámica en el sentido de que admite el juego de varios sistemas que operan, 
superpuestos, a la vez. Es común que en la valoración compleja se dé preeminencia a uno sobre los otros sistemas de valores en una jerarquía que debe inferirse empíricamente en cada caso. Como el sentido otorgado por los humanos a cualquier cosa en las cuatro formas de valoración (digamos, a un lingote de oro) es siempre simbólico, el sentido estético es, por así decir, reduplicativamente simbólico: se refina el simbolismo general de las cosas porque se lleva al extremo.

El ejemplo de los guaqueros sirve bien. Es posible que sus antecesores españoles estuvieran sólo interesados en el valor comercial bruto — valor simbólico de cambio- del oro y por ello lo fundían; luego, saqueadores más refinados intuyeron que también la forma valía y no lo fundieron, pero pensaron que tanto la forma como la materia áurea acrecían su valor comercial, que predominaba. Es claro que un visitante contemporáneo con sensibilidad estética, digamos el arquitecto-arqueólogo A. Chaves, que reexcavó varias de estas tumbas, pudo ser consciente del valor comercial de lo allí contenido (si lo hubiera encontrado) pero dio preeminencia al valor simbólico reduplicativo del recinto entrando en "el sistema singular de metáforas" de que hablaba G. Kubler y recuerda C. Paternosto (I986, p. 6). ${ }^{6} \mathrm{Al}$ atender a este valor reduplicativo, que no excluye la atención a aspectos, por ejemplo, rigurosamente científicos, A. Chaves pidió y obtuvo el favor de que sus cenizas reposaran en una de las más complejas y bellas tumbas de la necrópolis, la $\mathrm{NS}_{20}$ (véala en 6. En el estudio E. Sevilla (2008a) se presenta un tratamiento detallado de la complejidad jerarquizada de los fenómenos de la cultura y del arte; allí se explican con ejemplos los sistemas complementarios de valores de uso, cambio, signo y símbolo y la noción de valor reduplicativamente simbólico. www.tierradentro.info). La cruz que resalta en el polvo, color de oro, del piso de la tumba marca el valor religioso, no sólo estético, de la significación compleja, reduplicativa en este caso.

Es una pretensión legítima de la arqueología, sobre todo de la del símbolo (Robb, J. E., I998), proponer, a partir de huellas que son cosas tangibles, materiales, conclusiones sobre las ideaciones y sensaciones de los pueblos pretéritos. La situación se hace en particular difícil por la ausencia, que no ocurre en Mesoamérica, de sistemas de registro escrito en cualquiera de sus formas, que permiten entrar por un medio comunicativo especial dedicado a transmitir sentido, en el mundo subjetivo de quienes produjeron o recibieron las obras que hoy nosotros denominamos arte. 
Con respecto al Tierradentro monumental prehispánico ha habido mucha especulación, incluso de respetados autores (cf. Sevilla, E., 2007a). Hoy, con paciencia y buen juicio los arqueólogos especialistas en el Alto Magdalena sientan algunas bases de inferencia convincente y nada especulativa. De ellas se hablará con brevedad enseguida, para concluir sobre la creencia (o suspensión de la descreencia) de nosotros, los visitantes de hoy, como sujetos individuales o colectivos.

\section{El sentido reduplicativamente simbólico en los productores-receptores originales}

NCONTRAMOS UN ENLACE CON LA ANTERIOR REFLEXIÓN SOBRE LA SUSPEN-

- sión de la descreencia (es decir, la creencia) en la expresión de uno de los arqueólogos líderes en la investigación sobre el Alto Magdalena, R. Drennan (2008, p. 383). Las observaciones empíricas realizadas por él y sus alumnos,

sustentan la conclusión de que el cemento social que mantuvo unidas las jerarquías sociales del Alto Magdalena en el Clásico Regional derivan más del campo de las creencias [beliefs] que de la economía, que sería por contraste un campo profano, es decir de descreencia [disbelief]. Esto concuerda con la sugerencia de que las tumbas monumentales y los rituales asociados eran la moneda principal de la competición a la muerte de un líder, en una sociedad cuyo liderazgo no estaba del todo institucionalizado (Langebaek, C. H., 2003) [subrayado del autor].

Líneas más arriba, con referencia a la estatuaria de San Agustín, el mismo arqueólogo escribió: "Por tanto, los individuos principales cuyas tumbas estaban acompañadas por esas estatuas pudieron haber sido chamanes, o sacerdotes, o líderes más seculares cuya autoridad estaba respaldada por un poder sobrenatural” (Drennan, R., 2008, p. 394). En esta línea de pensamiento, antes que Drennan y asociados, e incluso yendo más lejos, un autor (Engel, F., I976, p. 235) planteó la hipótesis de que los hipogeos fueron construidos como templos subterráneos y que pueblos invasores posteriores los utilizaron para depositar sus urnas funerarias. Estas creencias constituirían, o propiciarían, un estado de sensibilidad al que entrarían quienes, dejando la preocupación profana por la subsistencia y demás azares de la vida ordinaria practican, al entrar a las tumbas, la suspensión de 
la descreencia. Así entramos a plantearnos la función simbólica reduplicativa cumplida por obras materiales cuyos restos, mal que bien conservados, tenemos en la necrópolis del Parque. Al pensar en la función simbólica de artefactos que hoy llamaríamos "artísticos" para los productores y receptores originales en el vallecito de San Andrés, los apuntes del grupo de R. Drennan constituyen lo máximo que hoy podemos decir.

Es muy difícil separar la función reduplicativamente simbólica que llamaríamos "artística" de otras del mismo tenor, como la religiosa y la política, en tales sociedades, todas ellas basadas en creencias. E. Pasztory sostiene que muchas sociedades arcaicas, incluidas las andinas, tienen un notable número "de objetos formalmente sofisticados que parecen corresponder al concepto de arte propio de las sociedades que lo tienen" (2005, p. I89). También sostiene la noción, común en antropología, de que la función estética no viene sola, no es excluyente sino entreverada con otras funciones (2005, passim). Sólo en lo más alto de la evolución eurocentrada de la noción de arte y de la autonomización del mismo frente a la moral, la política y la economía, concretamente en la segunda mitad del siglo XIX y en Francia, fue posible pensar que el arte no tenía función (finalité sans fin), sólo la de existir, es decir "el arte por el arte". No fue un movimiento unificado ni una escuela, sino un pensamiento dominante, aunque vago y flotante, que pudo leerse en autores franceses como G. Flaubert, T. Gautier, R. Lecomte de Lisle, los Goncourt y C. Baudelaire (Cassagne, A. y Oster, D.,I997). Hoy suena más razonable pensar en un entramado social de tensiones, valoraciones e intereses varios, jerarquizados, en el que un artista, digamos G. Flaubert, tuvo que moverse para producir lo que produjo, la forma cómo lo hizo y el propósito con que lo hizo, es decir la función compleja de la obra. Para ver que sí había función simbólica reduplicativa, entreverada con otras, también simbólicas, de tipo moral, político, social y pedestre, basta leer, por ejemplo, los largos capítulos que sobre el agente productor llamado G. Flaubert escribió P. Bourdieu en su tratado Les règles de l'art (1992). Si esto ocurrió en Europa, en donde la autonomización del campo del arte fue un intento histórico sistemático, con mayor razón en otras sociedades, sobre todo arcaicas.

Sea lo que fuere del arte por el arte, los arqueólogos desde L. Binford (I962) buscaron resolver la cuestión de las variadas funciones de los elementos de la "cultura material" arqueoló- 
gica, entendida como conjunto de artefactos en determinado sitio y tiempo, con la triple distinción de artefactos tecnómicos, sociotécnicos e ideotécnicos. Liberada la distinción del contexto procesualista y positivista en que surgió (Renfrew, C. y Bahn, P. G., 2005, p. 46), todavía es útil para abordar este tipo de cuestiones ideológicas (Silliman, S.W. y Hall, M., 2006, p. I29), aunque la diferenciación en el mismo L. Bindford entre lo sociotécnico y lo ideotécnico no sea tan clara como entre estas categorías y la de lo tecnómico. Esta se refiere, según el autor (Binford, L., I962, p. 219) a "aquellos artefactos cuyo contexto funcional primario está en entenderse directamente con el medio físico". Como todo producto concreto de la agencia humana implica alguna función simbólica, así sea elemental, la distinción no es tan clara. Es preferible entonces hablar de énfasis sobre algún aspecto del sentido (propósito, valoración) que por lo general es complejo, jerarquizado y dinámico. Enterrar a un muerto es una acción tecnómica si se piensa sólo en deshacerse de un elemento orgánico que se descompone y huele mal; no obstante, a esta acción los humanos añaden funciones no tecnómicas, es decir sociotécnicas e ideotécnicas. La necrópolis de Tierradentro como otras prácticas referentes a los cuerpos de los muertos son elaboraciones en particular refinadas de estas funcionalidades reduplicativamente simbólicas (Domanska, E., 2005).

Desde el punto de vista de la antropología del arte la cuestión puede plantearse si acudimos a la idea de E. Pasztory (2005, p. II), quien asigna una función cognitiva dominante a todos los artefactos humanos, que incluye los que se denominan arte. Estos últimos tienen una especialidad:

La capacidad informacional de algunos objetos [artefactos] es mayor - y diferente en forma- que la de otros, porque desde el tiempo de los humanos tempranos algunas cosas fueron primariamente para fines de comunicación. Los medios de comunicación fueron estéticos pero los propósitos no. [Subrayado añadido, para marcar el énfasis de un proceso que es complejo y jerarquizado].

Cuando la autora habla de medios estéticos (p. Io) se refiere a las propiedades formales y al estilo, por ejemplo de puntas de proyectiles líticos (Clovis o Folson) que pudieron ser discernidos por los productores-usuarios originales como lo son por los arqueólogos siglos o milenios después. Recuérdese a F. Boas (1928) y lo que escribió sobre el estilo y el virtuosismo. Eran sin 
duda artefactos primariamente tecnómicos pero con propiedades simbólicas, que E. Pasztory denomina estéticas. Son inherentes a la existencia del artefacto y en algunas sociedades arcaicas como las andinas prehispánicas se mantuvieron implícitas.

Volviendo al caso de las creencias que en R. Drennan permiten entender la función de los montículos, tumbas y estatuaria del Alto Magdalena con respecto a la diferenciación social y jerarquías de poder propio de los cacicazgos, habría que tener, además de lo dicho con anterioridad, el párrafo con que dos andeanistas muy reconocidos (Silverman, H. e Isbell, W., 2002, p. 9) resumen el pensar generalizado de antropólogos y arqueólogos con respecto a las sociedades centroandinas prehispánicas:

La mayoría de los investigadores modernos parecen compartir, con sus contrapartes más tempranas, la aceptación básica de la existencia de una cultura fundamental andina a través del espacio y el tiempo. El arte antiguo andino es visto como el reflejo de una visión cosmológica y de principios compartidos de una organización social y estructura andina. También, hoy se reconoce que la religión no era un campo separado de la vida en las sociedades antiguas. Mientras Tello y otros investigadores peruanos se preocuparon, por ejemplo, por identificar los dioses del antiguo panteón andino, los arqueólogos contemporáneos miran la religión y la vida social, política y económica como anidadas en una cosmología de la sociedad, una visión del mundo, una concepción de la estructura propia del orden social y una organización sociopolítica.

De hecho, los investigadores liderados por R. Drennan en el Alto Magdalena trabajan por desvirtuar para esta zona la tesis simplista de que la diferenciación social y las jerarquías de poder en los llamados cacicazgos tenían sus bases directas, cuasimecánicas, en determinantes económicos y tecnoambientales (control de recursos estratégicos). Hasta hoy, dichos investigadores lidian con huellas de asentamientos, con calidad de suelos, con cerámica, con basureros y con inferencias demográficas para explorar su relación con los centros en donde aparecieron estatuas, montículos y tumbas. En cuanto a la función simbólica en ello están y estarán por algún tiempo. El apelar a las creencias y a un dominio sobrenatural que estaría detrás del poder y la jerarquía es una alternativa que apenas comienza a ventilarse y que ofrece enormes dificultades de inferencia científica a partir de los duros datos materiales con que ellos trabajan. 
La opción mesurada de los arqueólogos del Alto Magdalena inspirados por R. Drennan se encuentra a medio camino entre dos

7. Véase, por ejemplo, el acrobático vuelo interpretativo de 4.000 años que - dentro de este estilo de hacer arqueología del símbolo_ hacen T. Grieder y asociados (2002) de los colores y diseños logrados en la cerámica prehispánica de Challuabamba, Ecuador (4200-3200 AP): "Colores simbólicos, especialmente rojo (sangre, vitalidad, día) y negro (protección espiritual, tierra, noche, bajo mundo) están entre los más antiguos símbolos de esta cosmología". Más de una vez hemos escuchado este tipo de interpretaciones de los emblemáticos colores, también rojo y negro sobre blanco, comunes en las pictografías de las tumbas de Tierradentro. excesos que se han dado: por un lado el determinismo tecnoambiental y económico y, por otro, el fácil recurso de apelar a un simbolismo universal (que hoy compartiríamos, como humanos, con la gente preshipánica) para aventurarse a osadas elucubraciones de interpretación a partir de la iconografía lítica disponible y de resonancias simbólicas subjetivas propias cuando entramos

a las tumbas, apreciamos el paisaje o miramos una estatua. El recurso fácil a la analogía etnográfica es a veces una excusa para estos devaneos. $^{7}$

En un estudio reciente se llamó mitopoéticas a algunas de estas apreciaciones en tanto se presentan como referidas al pasado prehispánico y carecen de un convincente sustento empíricoinferencial (Sevilla, E., 2007a). E. Pasztory (2005, p. 49-50), citando a N. Munn (1973) y su estudio de la iconografía walbiri en Australia, es categórica en recordarnos que decodificar el sentido de los diseños sin la ayuda de sus autores-receptores es imposible:

En la narración [de N. Munn] diseños del mismo símbolo —un círculo o una línea- pueden estar por muchas cosas —un sol, un ojo de agua, un camino, una vara de pesca. El sistema simbólico no está establecido sino que es fluctuante y multivalente. Esas imágenes fueron creadas para cubrir las necesidades de un pequeño grupo de gente que las entendió específicamente en relación con sus mitos y mapas o fueron explicadas a medida que se estaban haciendo.

N. Munn hizo su etnografía con un grupo de cazadores-recolectores (Munn, N., 2006), no con sociedades ya asentadas, incluso concentradas en aldeas, como fue el caso de Tierradentro en el período Medio o Tardío. El llamado de atención de H. Silverman y W. Isbell (2008) sobre algunos rasgos culturales panandinos puede abrir esperanzas que, por lo visto, son contrarrestadas por el drástico comentario de E. Pasztory. Es bueno estar alerta sobre excesos mitopoéticos cuando, por ejemplo, interpretamos qué quiso implicar para los constructores-receptores originales 
la combinación de "lunas" y "salamandras", distribuidos arriba y debajo de una línea tricolor horizontal que divide la bóveda de la tumba NAo en el Alto de El Aguacate (www.tierradentro.info).

\section{LOS VISITANTES DE HOY EN DÍA}

Como se dijo al comienzo, el Comité del Patrimonio Mundial DE la UNESCO hace una apreciación estética desde el punto de vista del visitante del siglo XX. Apela al criterio (i) de sus estatutos en donde menciona la "simetría simbólica" lograda entre las casas de los vivos y los muertos, la "agradable sensación estética" que causan las imponentes cámaras y, sobre todo, la "poderosa imagen de la importancia del nuevo estado en que el difunto ha entrado y la continuidad entre la vida y la muerte, entre los vivos y los ancestros". Habla del contacto con el "suelo primordial", aquel que los indígenas centroandinos denominan pachamama y los nasa de Tierradentro nasakiwe. Y concluye sobre la sensibilización que "la dignidad de las cámaras" procura con respecto a los "códigos y valores" de los productores-receptores originales. Se dijo antes que apreciación estética se toma en el presente estudio en un sentido muy cercano al que propone E. Pasztory (2005, p. 7I) cuando habla del "código de las cosas". En nuestro caso, estas son cámaras talladas en la roca viva, en algunos casos cubiertas de pinturas o con elaboraciones esculturales. Esas cosas con que nos encontramos al entrar a las cámaras tienen una fuerza intrínseca, algo así como el mana de que hablaron los antropólogos clásicos, que les permite comunicar sentido en forma diferente a como lo hace la escritura. Es una significación mucho más comprehensiva porque alude a todos los modos de sentir y pensar, no sólo al intelecto racional. Incluso, dice E. Pasztory, las cosas operan de modo más subliminal que la escritura y son poderosas porque hablan a la "mente subliminal" (p. 22). La fuerza estética de ciertos elementos no es misteriosa o mística, como se pensó del maná en tiempos clásicos de la antropología, sino que sus propiedades formales y estilo adquieren concreción de acuerdo con los niveles históricos precisos de desarrollo sociocultural que crean sentido, como cuando la autora habla de la superposición, multivalencia, estilización y realismo ocasional de las "obras de arte" de los cazadores recolectores o de la tridimensionalidad 
y performatividad integral de las máscaras en las sociedades aldeanas (p. 55).

Cuatro grandes categorías de sujetos pueden caber (y en ocasiones traslaparse) bajo el nombre genérico de los visitantes actuales de la necrópolis de Tierradentro:

(I) Los indígenas nasa que ocupan hoy el territorio y tienen a la necrópolis dentro de sus resguardos.

(2) Los otros ciudadanos colombianos, en sus diversas escalas y cercanías, desde los que viven en el corregimiento de San Andrés de Pisimbalá hasta los genéricos, pasando por los inzaeños y caucanos que saben que allí hay "un recurso" importante.

(3) Los visitantes, localmente llamados "turistas", que llegan graneados a ver la necrópolis, atraídos por la importancia que han oído decir tienen estos restos arqueológicos, que enmarcados en un llamativo paisaje natural y étnico, constituyen un buen ejemplo de lo que en términos de la avanzada del turismo cultural contemporáneo hoy se denomina "el espíritu del lugar".

(4) Los estudiosos e investigadores de varias disciplinas y artes, entre ellos, los antropólogos, arqueólogos, arquitectos y artistas.

Como los motivos y la expresión del interés son varios, por razones de espacio sólo nos detendremos en la tercera categoría, que es la que permite dar prioridad a la apreciación estética cuyo contenido sugiere la nota de la UNESCO. Como se dijo desde el inicio, ellos (nosotros) son los que con propiedad podrían hablar de arte, de prehispánico y de necrópolis. Además, como también se mencionó, es posible acercarse a la necrópolis bajo el efecto no de apreciación estética sino de otras inquietudes, entre ellas algunas bastante profanas (en el sentido de que se mantienen en el campo de la descreencia, ya comentada). Recuérdese que no hay valoraciones puras ni simples, sino complejas y jerarquizadas en planos de los que uno (no obligatoriamente el estético) es el dominante.

Desde el punto de vista aquí asumido, la relación de los sujetos visitantes con el "arte prehispánico" de la necrópolis puede plantearse en términos análogos a los que plantea F. Myers (2006, p. 268) con respecto a lo que, dentro de la tradición euro y anglocentrada, se denominó "arte primitivo". Esta designación ha causado mucha polémica, en particular a raíz de una muy sonada exposición de "arte-artefacto" montada por el Center for African 
Arts de Nueva York en I988 (Gell, A., 2006). Al fin y al cabo se trata de un arte producido por el otro distante, sea etnográfico o arqueológico, que se considera necesario para que el yo euro y anglocentrado y otros yos que, en contraste o a partir del mismo, buscan consolidar su propia ubicación existencial, es decir, construir su propia identidad. ${ }^{8}$ F. Myers, amplio conocedor y crítico de la experiencia actual con los artistas aborígenes australianos, sostiene que es posible destilar de ese arte otro, mediante un proceso de objetivación, "cualidades materiales" que tienen potencial para facilitar "nuevas lecturas e historias alternas". La objetivación es un proceso que permite

8. Sobre art premier, "arte otro", "arte primitivo", etcétera, escribí un ensayo que ganó el Premio Nacional de Crítica 2008, precisamente con referencia a ciertos diseños de las tumbas de Tierradentro y su relación formal con algunos diseños de los actuales nasa; véase E. Sevilla (2008b). advertir en los sujetos humanos un complejo vínculo con las cosas. Esa relación es dialéctica en el sentido de que es un va y viene entre la idea y la materialidad de los objetos (Tylley, C. Y., 2006). En el caso que tratamos, esos objetos son cámaras talladas y pintadas en la roca viva, con determinados antecedentes socio-históricos y, sobre todo, propiedades formales y de estilo establecidas. A esta capacidad de dar sentido a las cosas (que nunca están abstraídas de sus contextos históricos, desde luego) apela una noción de arte que supera el esteticismo occidental y considera crucial la experiencia generada en los sujetos vivos, aquella que J. Joyce denominó epifanía. Algunas cosas tienen más potencial de significación que otras, como dice E. Pasztory (2005). De este modo volvemos al punto focal del presente artículo, el de una visión diferente del arte como inserción en un sistema singular de valores, un sistema abierto de metáforas, del que el esteticismo occidental es una deformación sesgada y limitada (Paternosto, C., 1986).

Los visitantes de la necrópolis de Tierradentro son de muy variada condición como lo sugiere la clasificación cuatripartita y no excluyente mencionada. Entre ellos hay los que van por entretenimiento, por cumplir tareas escolares o científicas, por interés moral y político de construir nación (colombiana o indígena) o por un refinado "turismo cultural" que da prioridad a la apreciación estética. La UNESCO al hablar de "sobresaliente valor universal" apunta a algunos de los rasgos formales y de estilo, en especial los arquitectónicos, escultóricos y pictóricos, que pueden apoyar la construcción de experiencias estéticas en 
los visitantes dispuestos incluso a especular un poco sobre el sentido atribuido por las poblaciones originarias. Estas experiencias nuevas, nadie lo dude, se alimentan de la trayectoria intelectual y espiritual de cada visitante.

Por ejemplo, la UNESCO señala también el contacto inmediato con la madre tierra que en los Andes ha sido muy elaborado por los indígenas bajo las etiquetas de pachamama y nasakiwe y hoy alimentan de modo fuerte la construcción de sus identidades colectivas. La presencia dentro de las cámaras, si es posible penetrar hasta el fondo (lo que hoy se impide por barreras de guadua ubicada en las puertas) es una ocasión para captar con todo el cuerpo las incitaciones a la sensibilidad que esas construcciones procuran, incluso por el ambiente físico -interno, frío, semioscuro- y por el eco que responde, profundo y grave, a quien levanta la voz estremecida. El efecto no es sólo visual, como ha sido tradición en la apreciación del arte occidental hasta

9. "No sabemos lo que puede un cuerpo", es una frase clave en la Etica de Spinoza, que ha dado pie a G. Deleuze para elaborar una aproximación muy interesante a la apreciación estética. Ver su libro G. Deleuze (I98I) y C. Stalpaert (2002). mediados del siglo XX, sino total con todo el cuerpo, en el sentido espinoziano de una totalidad humana cuyas potencialidades desconocemos. ${ }^{9}$ Ese efecto puede potenciarse si uno logra, como se pudo hacer en una reciente investigación fotográfica, replicar de alguna manera el efecto luminoso, cálido y focalizado de una antorcha encendida que, esta vez, se hizo mediante un juego de luces eléctricas (fotografías que se presentan en www. tierradentro.info).

La variedad de experiencias estéticas propiciadas por las cosascámara abren diversos puntos de vista para la creación de las historias alternas de que habla F. Myers, según los visitantes, sus trayectorias y sus proyecciones. Hoy el turismo refinado de corte cultural, étnico y ambiental apunta a convertirse en ocasión de nuevas experiencias existenciales. Ellas propician un intercambio creativo (Richards, G. y Wilson, J., 2006) con otros pueblos y con materialidades de alto potencial significativo (Uriely, N., Yonai, D. y Simchai, D. Y., 2002; Uriely., 2005). Las "cosas" de piedra y pintura, reunidas en los cuatro altos de la necrópolis de Tierradentro, preñadas de sentido potencial por sus propiedades formales y de estilo, alimentan la sensibilidad a flor de piel que algunos turistas parecen llevar cuando entran en contacto con las mismas. El conocimiento sobre sus funciones sociotécnicas e ideotécnicas 
originales, que de modo paciente los arqueólogos intentan inferir, y las versiones mitopoéticas, que otros proponen con generosidad, refuerzan su capacidad de (como dice J. L. Borges de la verdadera poesía y del arte) distraernos y sobre todo de conmovernos. Por estas enormes potencialidades es, entonces, posible hablar de un arte prehispánico en la necrópolis de Tierradentro.

\section{Bibliografía}

Ayala, L. (1986). Las tumbas pintadas de Tierradentro. En E. Barney Cabrera, Director Científico. Historia del Arte Colombiano. Vol. I (pp. I88-2I2). Bogotá: Salvat Editores.

BECKer, H. S. (1982). Art Worlds. Berkeley: University of California Press.

BINFORD, L. R. (1962). "Archaeology as Anthropology”. American Antiquity 28(2): 217-225.

Boas, F. (1928). Primitive Art. Cambridge, Massachussetts: Harvard University Press.

Bourdieu, P. (1984). Mais qui a créé les 'createurs'? En P. Bourdieu. Questions de sociologie (pp. 207-22I). París: Les Éditions du Seuil.

. (1992). Les règles de l'art: genèse et structure du champ littéraire. París: Éditions du Seuil.

Cassagne, A. y Oster, D. (1997). La théorie de l'art pour l'art: en France chez les derniers romantiques et les premiers réalistes. París: Editions Champ Vallon.

Coleridge, S. T. (195I). Selected Poetry and Prose. Princeton: Princeton University Press.

Corporacion Regional del Cauca, CRC. (2002). Esquema de ordenamiento territorial Municipio de Inzá, Cauca. Disponible en: http://www.crc. gov.co/files/ConocimientoAmbiental/POT/inza/or-Introduccion.pdf. Consultado en septiembre 7 de 2009.

Chaves, A. y Puerta, M. (1980). Entierros primarios de Tierradentro. Bogotá: Fundación de Investigaciones Arqueológicas Nacionales, Banco de la República.

(I986). Monumentos arqueológicos de Tierradentro. Bogotá: Biblioteca Banco Popular.

(I988). Vivienda precolombina e indígena actual en Tierradentro. Bogotá: Fundación de Investigaciones Arqueológicas Nacionales, FIAN, Banco de la República. 
Danto, A. (1994). After the End of Art. En A. Danto. Embodied Meanings: Critical Essays and Aesthetic Meditations (pp. 32I-333). Nueva York: The Noonday Press-Farrar, Strauss and Giroux.

Deleuze, G. (I98I). Spinoza: Philosophie pratique. París: Les Éditions de Minuit.

Domanska, E. (2005). Toward the archaeontology of the dead body. Rethinking History, 9 (4): 389-4I3.

Drennan, R. D. (2008). Chiefdoms of Southwestern Colombia. En H. Silverman y W. H. Isbell (Eds.) Handbook of South American Archaeology (pp. 38I-403). Nueva York: Springer.

(2000). Las sociedades prehispánicas del Alto Magdalena. Bogotá: Instituto Colombiano de Antropología e Historia, ICANH.

ENGEL, F. (I976). An ancient world preserved: relics and records of prehistory in the Andes. Nueva York: Crown.

Fowler, W. R., BeEckman, C. S. y Pickering, R. B. (2006). Special Section: Mortuary Practices and Shaft Tombs in Western Mexico. An homenaje to Phil Weigand. Ancient Mesoamerica, I7, 3I-233.

GeLl, A. (1992). The Technology of Enchantment and the Enchantment of Technology. En J. Coote y A. Shelton (Eds.) Anthhropology, Art and Aesthetics (pp. 40-63). Londres: Oxford University Press.

. (2006). Vogel's Net: Traps as Artwork and Artworks as Traps. En H. Morphy y M. Perkins (eds.) The Anthropology of Art: A Reader (pp. 2I9-235). Malden: Blackwell Publishing.

Grieder, T., Farmer J. T., A. Carrillo y Jones, B. M. (2002). Art and Prestige Among Noble Houses of Equatorial Andes. En H. Silvervan y W. Isbell (Eds.) Andean Archaeology II: Art, Landscape and Society (pp. 157-I77). Nueva York: Kluber Academic, Plenum Publishers.

GutiéRrez, S. DE y L. DE GARCíA. (s.f.). Trabajo sobre tumbas en Colombia: culturas subandinas. Bogotá. Documento inédito.

Ford, J. A. (I944). Excavations in the vicinity of Cali, Colombia. New Haven: Yale University Press.

International Council of Monuments and Sites, ICOMOS. (2008). What is OUV? Defining the Tutstanding Universal Value of Cultural World Heritage Properties. París: UNESCO, ICOMOS.

Langebaek, C. H. (2003). The Political Economy of Pre-Columbian Gold Work: Four Examples from Northern South America. En J. Quitter y J. W. Hoppes (Eds.) Gold and Power in Ancient Costa Rica, Panama and Colombia (pp. 245-278). Washington: Dumbarton Oaks Research Library and Collection. 
Langebaek, C. H. (Ed). (I998). Arqueología de Tierradentro: Procesos de cambio social del 1.000 a. C. al presente en una región de Colombia. Informe de investigación. Bogotá: Instituto Colombiano de Antropología e Historia, ICANH.

Langebaek, C. H. y Dever, A. (2009). Arqueología regional en Tierradentro, Cauca, Colombia. Revista Colombiana de Antropología, 45 (2).

Langebaek, C. H., Dever, A. y Blick, J. (200I). Arqueología en Tierradentro: cambios sociales y ocupación del espacio. En G. Barona y C. Gnecco (Eds.) Historia, geografía y cultura en Cauca: Territorios posibles. Tomo II (pp. 325-338). Popayán: Universidad del Cauca, Corporación Autónoma Regional del Cauca, Lotería del Cauca.

LoNG, S. (I967). Formas y distribución de las tumbas de pozo con cámara lateral. Separata de la Revista Razón y Fábula, I: I-I2.

Mauss, M. (I950). Esquisse d’une théorie générale de la magie. En Sociologie et anthropologie (pp. I-I4I). París: Quadrige, Presses Universitaires de France.

Myers, F. (2006). "Primitivism”, Anthropology and the Category of "Primitive Art”. En Christopher Y. Tilley, Keane Webb y P. Spyer (Eds.) Handbook of Material Culture (pp. I-5I). Sage. Thousand Oaks, California.

Nehamas, A. (I985). Nietszche: Life as Literature. Cambridge: Harvard University Press.

Munn, N. (1973). Walbiri Iconography. Ithaca: Cornell University Press. (2006). Visual Categories: An Approach to the Study of Representational Systems. En H. Morphy y M. (Eds.) The Anthropology of Art: A Reader (pp. 326-338). Malden: Blackwell Publishing.

Paternosto, C. (I986). The Stone and Thread: Andean Roots of Abstract Art. Austin: The University of Texas Press.

Pasztory, E. (1997). Andean Aesthetics. En K. Berrin (Ed.) The Spirit of Ancient Peru: Treasures from the Museo Arqueológico Rafael Larco Herrera (pp. 4I-59). Nueva York: Thames and Hudson. Reproducido en E. Pasztory (2005).

(2005). Thinking with Things: Toward a New Visión of Art. Austin: University of Texas Press.

Preciado, G. (I996). Restauración arquitectónica para los hipogeos de Tierradentro. Tesis de Maestría, Universidad Autónoma de México.

Quattrin, D. W. (200I). Prehispanic Chiefdoms in the Valle de La Plata. (Vol. 4). Vertical Economy, Interchange, and Social Change during the Formative Period. Pittsburgh-Bogotá: University of Pittsburgh Memoirs in Latin American Archaeology II. 
Renfrew, C. y BaHn, P. G. (2005). Archaeology: the Key Concepts. Londres: Routledge.

Richards, G. y Wilson, J. (2006). Developing Creativity in Tourist Experiences: A Solution to Serial Reproduction of Culture? Tourist Management, 27: I209-I223.

Roвb, J. E. (I998). The Archaeology of Symbols. Annual Review of Anthropology, 27: 229-246.

SEvilla, E. (2007a). Los animales mágicos de Tierradentro imagia de quién? International Journal of South American Archaeology, i: 67-79. También disponible en: www.tierradentro.info. 5: 24I-274.

(2007b). Verdades y redescripciones etnográficas. Antípoda

(2008a). Gestores culturales para el Valle del Cauca. Documento Maestro para un Programa de Profesionalización de Gestores Culturales en la Universidad del Valle. Cali: Facultad de Artes Integradas, Universidad del Valle. También disponible en: www.tierradentro.info.

(2008b). "Tierradentro: les arts premiers y la jigra de la vida". En Universidad de los Andes y Ministerio de Cultura (Eds.) Ensayos sobre arte contemporáneo en Colombia 2007-2008. Bogotá: Universidad de los Andes (Ensayo ganador, Premio Nacional de Crítica Ministerio de Cultura y Universidad de los Andes).

(2009). Informe final del Proyecto Tierradentro, No. 398. Bogotá: Banco de la República, Fundación de Investigaciones Arqueológicas Nacionales, FIAN. También disponible en: www. tierradentro.info.

Sevilla, E. y Piñacue, J. C. (2008). Los nasa y las huellas arqueológicas, primera aproximación. En H. Henderson (Ed.) Navegando el cambio: Estudios recientes en práctica y agencia. Bogotá: Universidad Nacional. En prensa.

Silliman, S. W. y Hall, M. (2006). Historical Archaeology. Londres: Blackwell.

Silverman, H. E Isbell, W. (2002). From Art to Material Culture. En H. Silvervan y W. Isbell (Eds.) Andean Archaeology II: Art, Landscape and Society (pp. 3-20). Nueva York: Kluber Academic, Plenum Publishers.

Stalpaert, C. (2002). Donnez-moi donc un corps": Gilles Deleuze's aesthetics of Intensities and the Possibilities of Queer Postrepresentations. Disponible en: http://en.scientificcommons.org/4I3II948.

TAYlOR, R. E. (I97O). The Shaft Tombs of Western Mexico: Problems in the Interpretation of Religious Function in Nonhistoric Archaeological Contexts. American Antiquity, 35 (2): 160-169. 
Tylley, C. Y. (2006). Objectification. En C. Y. Tilley, K. Webb y P. Spyer (Eds.) Handbook of Material Culture (pp. 60-73). Thousand Oaks: Sage.

UNESCO, World Heritage. (I995). Site Tierradentro, No. 743 "Advisory Body Evaluation”. http://whc.unesco.org/en/list/743/documents/ Consultado en septiembre 7, 2009.

Uriely, N. (2005). The Tourist Experience: Conceptual Developments. Annals of Tourism Research, 32: 199-216.

Uriely, N., Yonay, Y. y Simchai, Y D. (2002). Backpacking Experiences: A Type and Form Analysis. Annals of Tourism Research, 29: 519-537.

Vogel, S. (2006). Introduction to Art/Artifact: African Art in Anthropology Collection. En H. Morphy y M. Perkins (Eds.) The Anthropology of Art: A Reader (pp. 209-2I8). Malden: Blackwell Publishing.

Williams, R. (I976). Keywords. Glasgow: Fontana Press. 